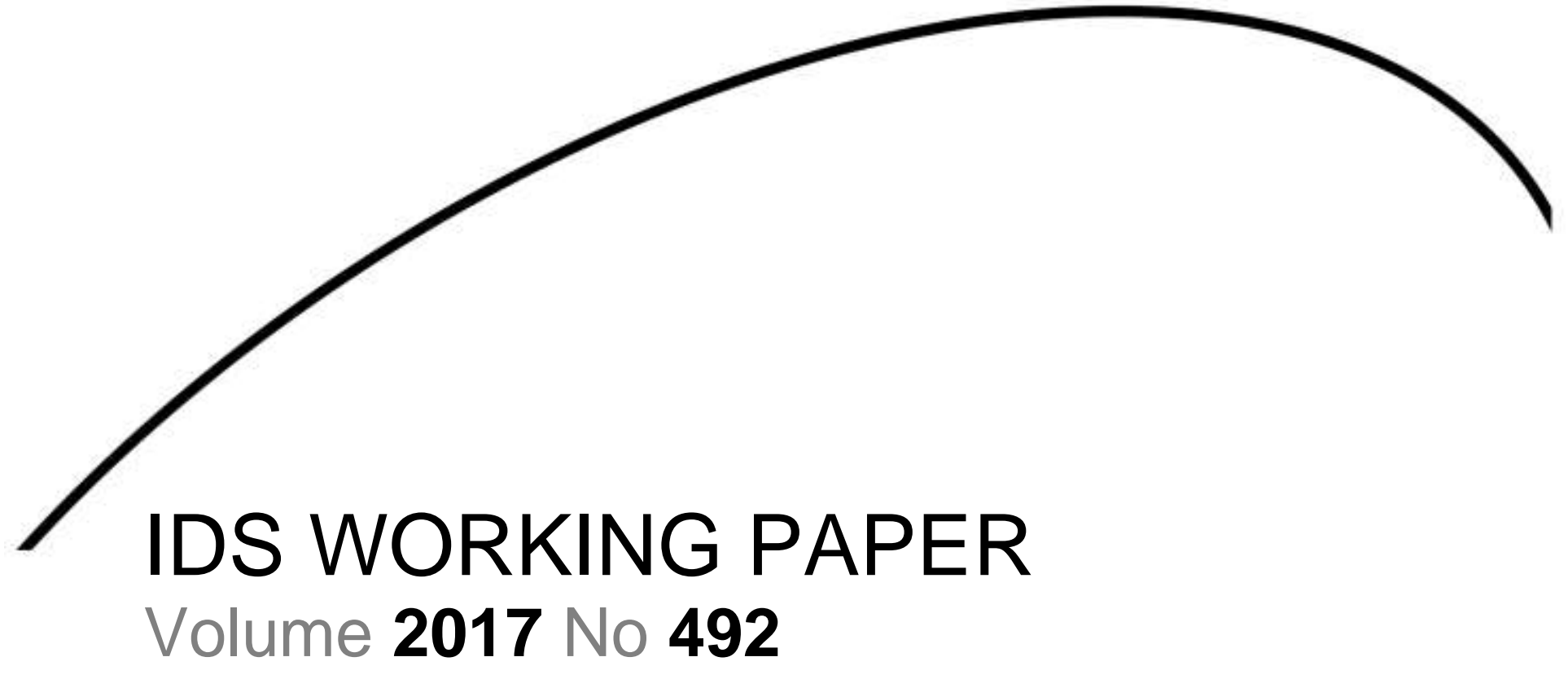

Assessing the Role of Social Media and Digital Technology in Violence Reporting

Tony Roberts and Gauthier Marchais

August 2017 
Assessing the Role of Social Media and Digital Technology in Violence Reporting Tony Roberts and Gauthier Marchais

IDS Working Paper 492

(C) Institute of Development Studies 2017

ISSN: 2040-0209 ISBN: 978-1-78118-385-4

A catalogue record for this publication is available from the British Library.

All rights reserved. Reproduction, copy, transmission, or translation of any part of this publication may be made only under the following conditions:

- with the prior permission of the publisher; or

- with a licence from the Copyright Licensing Agency Ltd., 90 Tottenham Court Road, London W1P 9HE, UK,

or from another national licensing agency; or

- under the terms set out below.

This publication is copyright, but may be reproduced by any method without fee for teaching or nonprofit purposes, but not for resale. Formal permission is required for all such uses, but normally will be granted immediately. For copying in any other circumstances, or for re-use in other publications, or for translation or adaptation, prior written permission must be obtained from the publisher and a fee may be payable.

Available from:

Communications and Engagement Unit, Institute of Development Studies, Brighton BN1 9RE, UK

Tel: +44 (0) 1273915637

E-mail: bookshop@ids.ac.uk

Web: www.ids.ac.uk/publications

IDS is a charitable company limited by guarantee and registered in England

Charity Registration Number 306371

Charitable Company Number 877338 


\title{
Assessing the Role of Social Media and Digital Technology in Violence Reporting
}

\author{
Tony Roberts and Gauthier Marchais
}

\begin{abstract}
Summary
The use of social media and digital technologies has radically changed the way that information about violence is captured, reported, analysed and acted upon. People's use of social media played a significant role in the Egyptian revolution, post-election violence in Kenya, and drug-cartel violence in Mexico. Social media can be used to provide humanitarian agencies, policymakers and academics seeking to understand and respond to violent crises with data unavailable from other sources. After an initial period of uncritical optimism regarding the potential of social media and digital technologies there is now, however, a growing recognition that they come with new practical, ethical and methodological limitations. Indeed, social media content is often the target of conscious distortions, manipulations, or censorship by a range of actors. Bias of several kinds can significantly distort social media data and reduce their representativeness. This paper assesses the role of social media and digital technologies (SMDTs) in the reporting of violent events, and evaluates their relative strengths and weaknesses as compared to other means available. It seeks to understand how SMDT data are collated, how reliable the data are, and what practical and ethical issues are associated with their collection and use. We start by situating the application of these technologies within the wider discussion of the use of information and communication technologies for development (ICT4D) and the sub-field of real-time data for development (RTD4D), before presenting the different types of SMDT data collection instruments and methods. We then assess the reliability of SMDTs for the reporting of violent events, identifying potential factors of biases in the data, such as geographical coverage, demographic and socioeconomic factors, or biases resulting from the nature and configuration of violent events. We also look at whether such data can accurately capture underlying dynamics of violent events. Finally, we look at the practical and ethical challenges associated with the collection of SMDT data on violent events.
\end{abstract}

Keywords: Social media and digital technology; violence; conflict; reporting of violence; conflict events; methodology.

Tony Roberts is a Research Fellow in the Digital and Technology cluster at the Institute of Development Studies. He has been working in digital development and social justice since 1988 as a volunteer, lecturer, practitioner, trustee and researcher. Tony was founder and CEO of two international development agencies before completing doctoral research on women's use of participatory video to challenge gender injustice in Zambia's technology sector. His research focuses on the intersection of power, participation and technology.

Gauthier Marchais is a Research Fellow in the Conflict and Violence cluster at the Institute of Development Studies. He recently completed a PhD at the London School of Economics and Political Science on the dynamics of participation in armed groups in eastern Democratic Republic of Congo, and has been involved in several research projects focused on the region. 


\section{Contents}

Summary, keywords and author notes 3

Acknowledgements and Acronyms 5

$1 \quad$ Introduction $\quad 6$

1.1 Capturing violence data using SMDTs: a new panacea? 6

1.2 Background: Digital technology in humanitarian aid and development 8

1.2.1 Active crowdsourcing of small data 9

$\begin{array}{ll}\text { 1.2.2 Passive crowdsourcing of big data } & 10\end{array}$

$\begin{array}{ll}1.2 .3 \text { Crowdseeding } & 11\end{array}$

$2 \quad$ Analysing SMDT data on violent events 12

2.1 Geographic and spatial bias in violence reporting 13

2.2 Demographic bias in social media access 13

$2.3 \quad$ Social and gender norms 16

2.4 Measurement error due to the nature and characteristics of violent events 17

$\begin{array}{ll}2.5 & \text { Capturing underlying mechanisms of violence } 20\end{array}$

$3 \quad$ Beyond data collation $\quad 22$

$\begin{array}{ll}3.1 & \text { Towards actionable data } \\ 3.2 & 22\end{array}$

3.2 Ethical challenges of social media data use 24

$\begin{array}{ll}3.3 & \text { Concluding remarks and recommendations } \\ \end{array}$

$\begin{array}{lr}\text { References } & 28\end{array}$

\section{Figures}

Figure 1.1 Gartner's technology hype cycle 7

Figure 1.2 Ushahidi online map of unfolding violence during Kenyan elections 10

Figure 1.3 Typology of social media monitoring 12

Figure 2.1 Social media access: the five 'A's 15

Table

Table 3.1 Comparative (dis)advantages of violence reporting media 


\section{Acknowledgements}

The authors are indebted to four anonymous reviewers as well as to Anand Sheombar from Hogeschool Utrecht, Andres Moreno from the United Nations University, Computing and Society Research Institute and to Sonia Sinanan for their invaluable inputs to this paper.

The support of the Economic and Social Research Council (ESRC) (UK) is gratefully acknowledged. The opinions expressed are those of the authors and do not necessarily reflect the views of IDS or the ESRC.

\section{Acronyms}

A4Al

ACLED

API

App

CSO

DRC

GDELT

ICT

ICT4D

ISPS

OECD

RTD4D

SMS

SMDT

UCDP

UK

UN

USA

Alliance for Affordable Internet

Armed Conflict and Location and Event Data Project

Application Programme Interface

mobile application

civil society organisation

Democratic Republic of Congo

Global Data on Events, Location and Tone

information and communication technologies

information and communication technologies for development

internet service providers

Organisation for Economic Co-operation and Development

real-time data for development

short messaging system, for sending text messages between mobile phones

social media and digital technology

Uppsala Conflict Data Program

United Kingdom

United Nations

United States of America 


\section{Introduction}

\subsection{Capturing violence data using SMDTs: a new panacea?}

Our use of social media and digital technologies (SMDTs) is profoundly transforming the way violent events are reported, analysed and acted upon. Social media platforms such as Twitter, Facebook and WhatsApp allow ordinary members of the public to use their mobile phones or other digital devices to broadcast their personal reports widely, or to narrowcast them to private, shared interest groups. These new information and communication tools have been key in reducing previous information asymmetries in contexts of highly unequal confrontations, such as the Arab Spring uprisings (Zhuo et al. 2011), or the anti-globalisation demonstrations in Pittsburgh (Earl et al. 2013). SMDTs are also used for coordinating violent forms of collective action by a range of actors, ranging from street gangs, rebel groups, and mafias to 'terrorist' networks and nation states. SMDTs are now widely used by state and non-state actors as a means for the monitoring and surveillance of political unrest and armed conflict.

Social media content and data have revealed forms and types of violence previously invisible and under-reported in traditional media due to reporting biases (Weidmann 2015; Baum and Zhukov 2015). The ready availability of mobile phones with the capability to take photos and video footage and to upload them to Facebook or Instagram enables citizens to provide much more immediate, and detailed, visual and textual evidence of violence than had previously been available via mainstream media. Black Lives Matter and the Occupy Movement are examples of civil society organisations (CSOs) who have used social media successfully to circumvent mainstream media's ambivalence to police violence against African-Americans and growing social inequality, turning social media into a powerful tool for advocacy and collective action. Social media content has also been used to reveal state violence and torture in Abu Ghraib (Amnesty 2006) and the secret drone wars being waged by the United States of America (USA) in Pakistan, Yemen, Somalia and elsewhere (Strasser 2013).

Social media use is also radically transforming the way humanitarians, policy actors and academics engage with violent events, as they offer significant advantages over traditional media, including the ability to capture more instances of more granular information about on-the-ground realities, and the potential to visualise, verify and validate it in near real-time (Sambuli et al. 2013). As information is both crucial and often scarce in times of crisis, the capacity to collect real-time situational data using such technologies has the potential to significantly improve early warning systems and to provide enhanced information for decision-making in relation to security and the targeting of interventions and humanitarian aid. It can also enhance the quantity and quality of 'evaluative data', such as monitoring and evaluation systems, internal audit, and accountability procedures (Read et al. 2016).

Enthusiasm for such technologies in the development and humanitarian sectors has been high. In their report Preventing Violence, War and State Collapse the Organisation for Economic Co-operation and Development (OECD) recommended that member states recognise 'the critical importance of adopting innovative information and communication technologies for data collection, communication, visualisation and analysis' (OECD 2009). Similarly, the United Nations (UN) High-Level Panel on the Post-2015 Development Agenda called for a 'data revolution', which 'would draw on existing and new sources of data to fully integrate statistics into decision-making, promote open access to, and use of, data' (UN 2013). With regards to violent crises specifically, one of the most significant advances has been the development of crowdsourcing platforms that enable actors to monitor violent episodes through the aggregation and mapping of social media data. The Ushahidi platform is an early example of SMDT use by local citizens to monitor unfolding electoral violence during Kenya's 2007 elections (Makinen and Wangu Kuira 2008) and, later, to monitor 
elections in countries including Sierra Leone, Nigeria and Ghana (Moreno et al. 2017). Crowdsourcing tools like Ushahidi have also been used to map unfolding humanitarian disasters such as earthquakes and typhoons in a practice called 'crisis mapping', again using citizen-generated data to visually map and document unfolding crisis situations (Gao et al. 2011; Meier 2012). Although a critical review of humanitarian technologies is beyond the scope of this paper, see for an example the work of Madianou, Longboan and Ong (2015).

Social media and digital technologies have also generated significant enthusiasm in academia, as they give researchers the potential to enhance the quantity and quality of data available for research on violent conflict. Falling costs of digital data collection devices such as tablets and smartphones have reduced barriers to carrying out surveys on violent events in conflict-affected areas. They enable researchers to capture the micro-level dynamics of violent conflict events through the collection of fine-grained, disaggregated data (Blattman and Miguel 2010; Bruck et al. 2015). They also make it possible to capture the temporal dimension of violent events more accurately, the analysis of which was previously limited by the lack of historical data and the reliance on cross-section-type data, which does not allow for temporal analysis.

History cautions that emerging technologies are often accompanied by uncritical overenthusiasm in which we overestimate the effect of technologies in the short term. Gartner (2016) characterises this phenomenon as a 'technology hype cycle' in which an early flush of inflated expectations predictably precedes a later trough of disappointment (see Figure 1.1). Read et al. (2016) have warned about the 'data hubris' that has permeated the aid, humanitarian and academic spheres.

\section{Figure 1.1 Gartner's technology hype cycle}

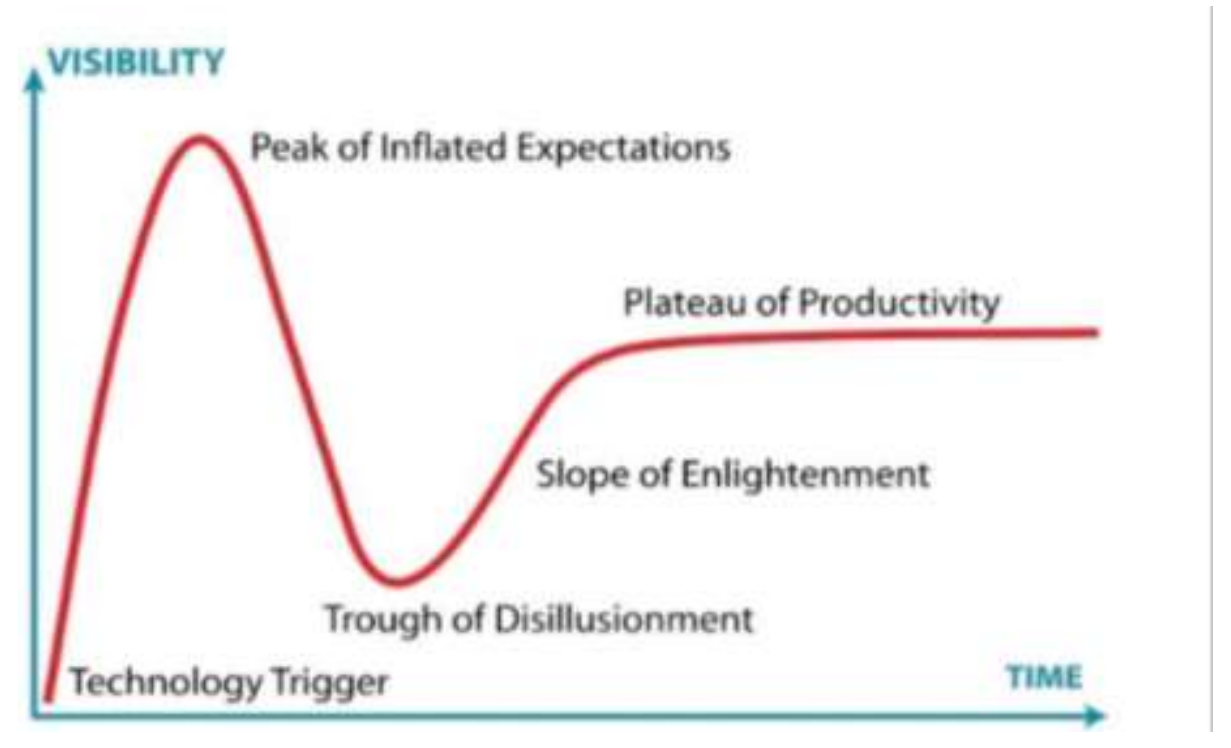

Source: Gartner Inc. (2006), reproduced with kind permission.

Like any other type of data, data generated through SMDTs are subject to issues of reliability and bias. Data collected through platforms such as Twitter have been shown to be fraught with potential biases resulting from the architecture of these social media platforms and restrictions of access to the data (Boyd and Crawford 2011). Ownership of these platforms also poses a range of questions with regards to political interference and potential manipulation or alteration of the data. Data on violent events present a range of additional challenges. Unequal access to SMDTs in conflict-affected areas, social norms about what constitutes violence, manipulation, and falsification of content by powerful actors which are likely to be exacerbated in violent contexts are among the factors that can generate systematic biases in social media data on violent events. 
As a result, certain types of violent events can be systematically under-reported in social media data, which can have severe political and humanitarian consequences. Furthermore, the fact that SMDTs enable data collection in real-time does not make them immune to measurement error, or to inaccuracies of spatial or temporal patterns. Assessing the accuracy of social media data in capturing these patterns as well as the social, political and economic mechanisms that underpin and enable violent events is therefore crucial for their usage in academic research. Furthermore, the lower cost of SMDT methods does not entail ease of implementation. In high-risk settings where data collectors can be subjected to violence, threats, repression and manipulation, data collection comes with significant additional material, logistic, financial, and ethical challenges which have to be carefully evaluated.

This paper analyses and assesses the relative advantages and disadvantages of the use of SMDTs to collect data on violent events. More specifically, we look at whether SMDT data are reliable for reporting and analysing violent events, the logistical and ethical challenges generated by the collection of such data, and the issues posed for informing policy, humanitarian action and academic research. The paper begins by situating this type of method within the growing information and communication technologies for development (ICT4D) literature, and presents the different types of SMDTs currently used to collect data on violence. In Section 2, we explore the question of reliability and accuracy of SMDT data, identifying key potential sources of biases in the data with regards to geographical coverage, demographic and socioeconomic factors, and biases due to the nature and configuration of violent events. We also discuss the potential of such data to accurately capture the social, economic and political processes that underpin violent events. In Section 3, we move beyond the analysis of SMDT data to understand the ways in which they can become 'actionable', and identify the logistical, financial and ethical challenges rising from the implementation of SMDT data collection methods.

\subsection{Background: Digital technology in humanitarian aid and development}

The increased use of SMDTs for violence reporting is part of a larger effort to harness new technologies for use in humanitarian aid and international development in what is sometimes called information and communication technologies for development (ICT4D). ICT4D is a growing field of practice and research concerned with understanding whether, to what extent, and under which circumstances the use of information and communication technologies (ICTs) can contribute to achieving development goals. We situate this paper within the field of ICT4D because of its focus on the intersection of digital technologies and international development and also because the interdisciplinary nature of ICT4D allows us to pull together relevant literature from multiple domains.

The continued rapid increase in the speed and capacity of ICTs, including the internet and mobile phones, coupled with their reducing cost have made possible a broad range of applications of ICT4D. However, whether ICTs should be viewed as a means to promote development is contested. Some scholars have argued that ICTs lead relatively straightforwardly to development outcomes: projects to build Digital Villages (Sachs 2005) or to provide One Laptop Per Child (Kraemer, Sharma and Dedrick 2009: 73) are examples of this theory of change. Others have claimed that ICT use in development is problematic and should not be promoted as a development solution, as to do so uncritically represents a form of neo-colonialism in which development is understood as the adoption of 'Western' culture and technologies (Ya'u 2004; Pieterse 2010).

The majority of ICT4D research and practice sits somewhere between these positions and focuses on the critical analysis of which factors contribute to, or inhibit, the productive use of ICT for development (Heeks 2009; Unwin 2009; Kleine 2013). 
Within this broader field of ICT4D lies the subfield of real-time data for development (RTD4D) which focuses on the use of 'live' data to inform action in near real-time. Examples of RTD4D include digital systems to remote-sense whether water pumps are working (ITU 2010), and the monitoring of social media to inform epidemiology during disease outbreaks (Salathé et al. 2012). Some real-time data for development systems are bespoke solutions, such as those designed to enable farmers to use short messaging system (SMS) text messaging to solicit today's price for the crop they are harvesting in several alternative local markets (World Bank 2011). Real-time market-price systems allow farmers access to 'small data' tailored to their specific needs. By contrast, 'big data' applications process huge data sets such as the billions of 'status updates', 'tweets' and 'posts' produced by citizens every day (Statistica 2017), and filter, collate and visualise them for analysis. By automatically and manually filtering datasets by location, date and time, and by using keyword searches, analysts aim to 'mine' big data in order to discern patterns early on and to produce actionable information that might prevent violent events or help to mitigate their effects. This report focuses on one specific area of real-time data for development which is the use of real-time social media data about violence, particularly 'crowdsourced' data.

The term crowdsourcing refers to the process of getting the general public (the crowd) to become a source of specific resources. Wikipedia, for example, is a crowdsourced encyclopaedia as the entries are produced by volunteers who author and upload the platform's content. Facebook and Twitter are social media platforms that effectively crowdsource their content as their users voluntarily author and upload status updates, photos and other content items. Sambuli et al. (2013) have characterised crowdsourcing as being either passive or active.

\subsubsection{Active crowdsourcing of small data}

Active crowdsourcing involves making a public call-to-action to provide specific information on a chosen topic to a dedicated telephone number, software platform or mobile application (app). This narrowly targeted approach is designed to generate small datasets that can be processed relatively easily to pinpoint critical events and lead to action. Ushahidi is the exemplar of active crowdsourcing of violence reports. The Ushahidi team in Nairobi used their social networks to share information about their platform and used social media to disseminate their call-to-action, which was for the crowd to send SMS reports of any election violence incidents to a dedicated number. Their core team then used these reports to populate a visual online map (Figure 1.2) which was successful in generating increased awareness among the public and global media of the unfolding events. Another example of the proactive crowdsourcing of small data on a pre-specified issue is the Jangbeeshi dedicated mobile app which was used to crowdsource reports live from polling stations during Ghana's 2012 elections. 
Figure 1.2 Ushahidi online map of unfolding violence during Kenyan elections

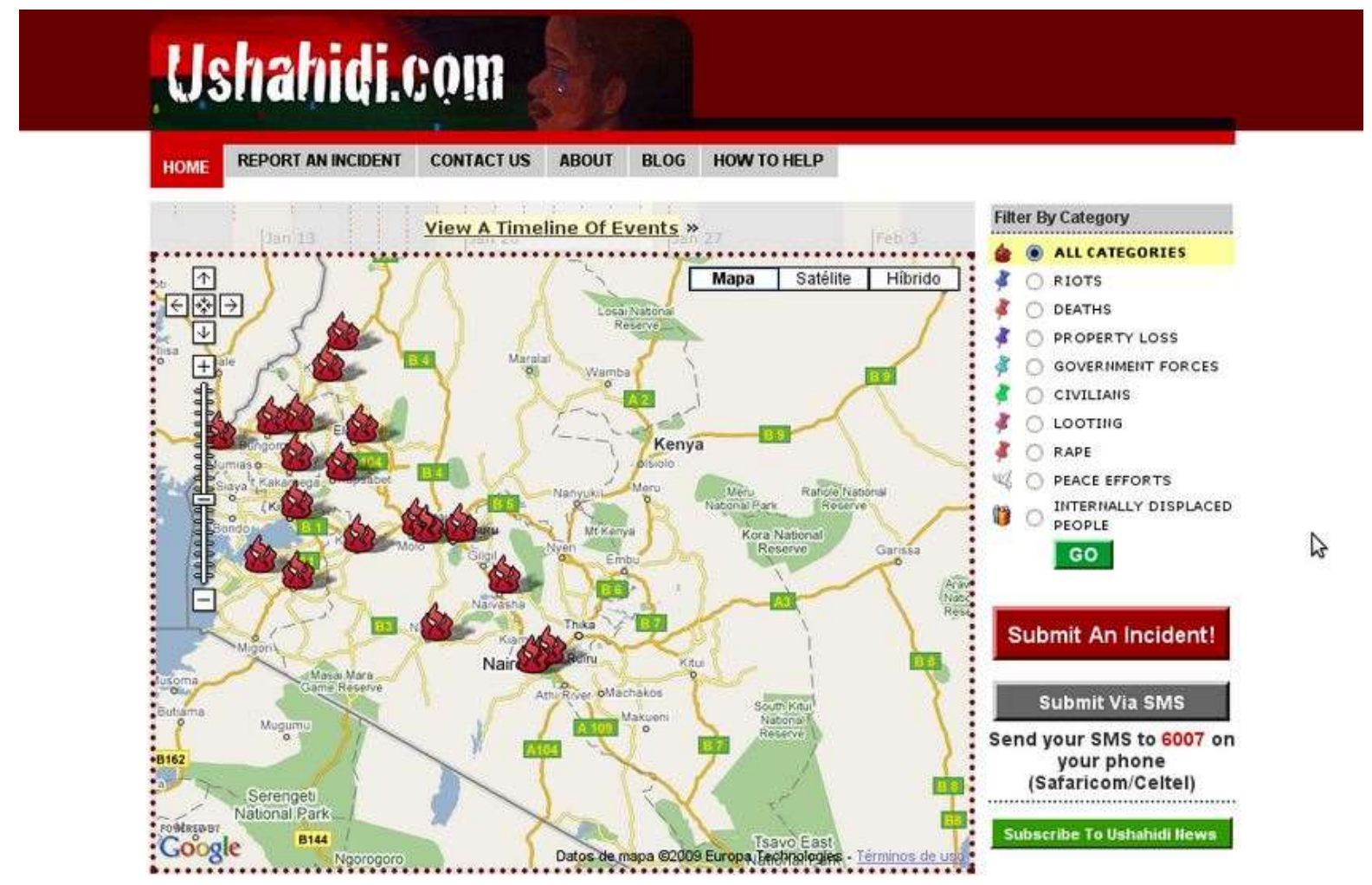

TAGS: ALL, Riots, Deaths, Property Damage, Government Forces, Chilians, Looting, Rape, Peace

Source: Ushahidi, reproduced with kind permission.

\subsubsection{Passive crowdsourcing of big data}

In contrast, 'passive crowdsourcing' involves no call-to-action or dedicated number. Instead it involves filtering the big data sets spontaneously produced by the crowd on social media platforms such as Twitter, Facebook or WhatsApp. Government intelligence and security forces 'passively' monitor social media big data traffic to detect criminal activity, including various dimensions of violence. An example of 'passive crowdsourcing' to detect violent events would be the use of 'Aggie' for election monitoring in Ghana (Moreno et al. 2017). Aggie is an open source software application used for aggregating social media to track realtime events such as election violence, humanitarian disasters or dangerous speech. No specific call-to-action is made; instead millions of publicly available social media updates are automatically filtered using keyword searches to locate specific content. When Aggie was used to monitor for violence during elections in Nigeria and Ghana, a 'situation room' was staffed by local civil society staff and journalists using SMDTs connected to the application programming interface (API) of Twitter and WhatsApp to extract messages mentioning keywords such as 'violence', 'gunshots', 'killed', etc.

Sambuli et al. (2013) used the 2013 Kenyan elections as a case study to directly compare passive crowdsourcing from Twitter with active crowdsourcing using Ushahidi. They found that passive crowdsourcing from Twitter produced a significantly larger number of critical incidents, but involved far more work filtering out background noise than the more targeted Ushahidi implementation with its very specific call-to-action. Each method has its strengths and weaknesses; in this case study the higher number of incidents captured by passive crowdsourcing and the need to manually filter out higher levels of irrelevant information added to the costs but the method delivered valued intelligence on a larger number of critical 
incidents. The active crowdsourcing had a better signal-to-noise ratio and therefore lower human workloads to analyse the data, but it delivered less critical incidents. Active and passive crowdsourcing rely on members of the public volunteering reports and, as a result, involve challenges of verification and systematic bias, issues which we will address in detail in the following sections.

\subsubsection{Crowdseeding}

Crowdseeding is a third modality for collecting SMS or social media reports of violent events. Instead of relying on unspecified volunteers to report violence as crowdsourcing platforms do, crowdseeding methods select and train specific data collectors to report violent events through SMDT. As a result, reporters can be selected using sampling methods to ensure geographic and demographic representation, and they can be equipped with mobile phones and call credit to ensure that they are able to provide specific types of information to a dedicated platform. This allows researchers an additional mechanism through which to control quality, representativeness and validation, which present significant challenges when sourcing data from the crowd, as we will discuss in the following section.

Voix des Kivus is an example of crowdseeding for the reporting of violent events in an active warzone. In the conflict-affected province of South Kivu, eastern Democratic Republic of Congo (DRC), three reporters were selected from each of the project's target villages to report all violent incidents occurring in the village (Van der Windt and Humphreys 2016). In relation to passive and active crowdsourcing, however, this method has relatively high costs. Whereas passive and active crowdsourcing rely on the crowd using their own mobiles and phone credit, this form of crowdseeding involves higher capital and revenue costs, as the project has to pay for the training of the researchers as well as the phones or reporting devices, and the telephone credit.

Amnesty International is using a novel form of active crowdsourcing to address the high costs of human processing of big data. They use a digital platform to enable the crowd to volunteer in the painstaking work of searching through thousands of satellite images of conflict affected areas of Darfur in order to isolate evidence of violent attacks. Amnesty has insufficient paid staff time to accomplish these tasks so it is using the digital platform to outsource the task to individual supporters working on their laptops or mobile phones. Each person is allocated one small section of the overall satellite imagery to search for identifiable indicators of violence. This active crowdsourcing of big data and then outsourcing the microtasking of processing the data enabled Amnesty to successfully decode 326,000 square miles of satellite images of Darfur (Marin 2017).

If we organise passive and active technologies into those relying on small data and dedicated platforms, and those that filter Big Data from non-dedicated platforms then we able to produce this useful typology for distinguishing violence monitoring SMDTs (Figure 1.3). 
Figure 1.3 Typology of social media monitoring

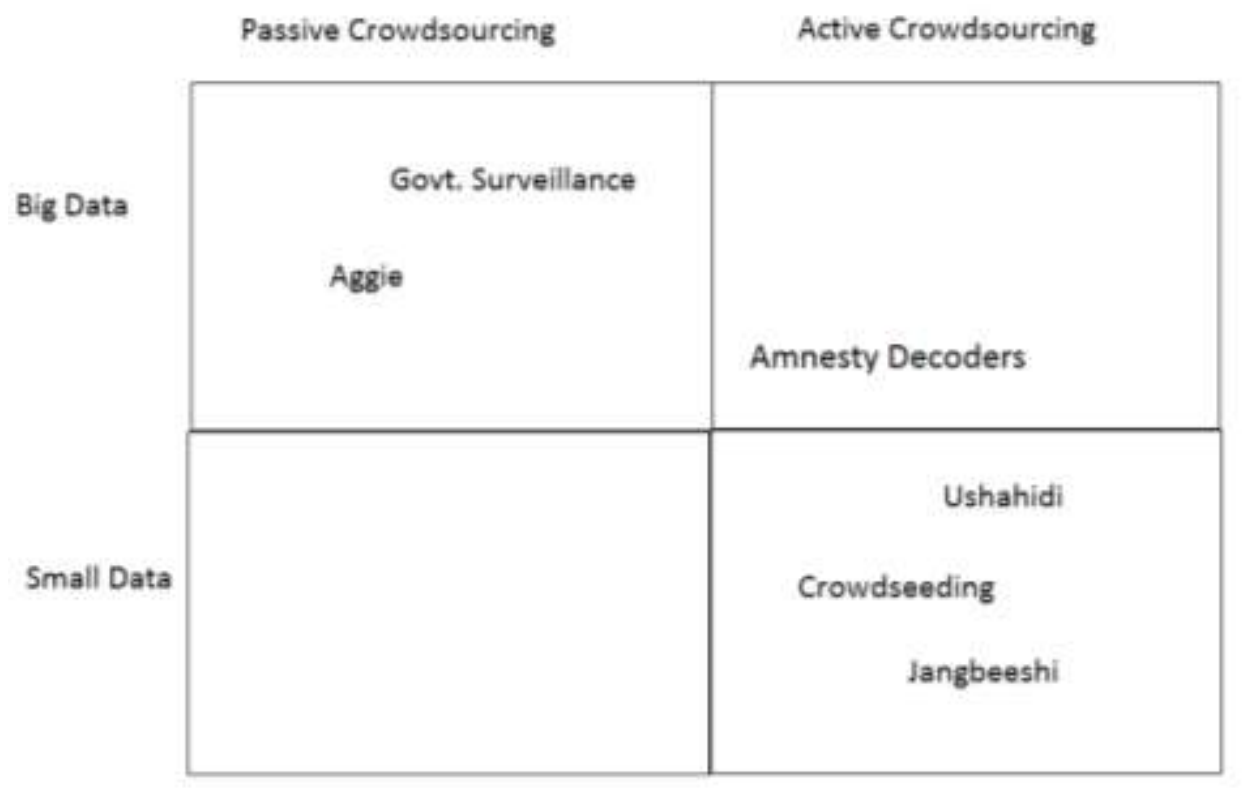

Source: Authors' own.

This section has located the use of social media and digital technologies in the wider context of ICT4D and real-time data for development. It has also described a range of technologies and modalities for crowdsourcing and crowdseeding data on violence events. Having examined the various ways in which violence data is collected and filtered, the next section will look at the specific challenges of analysing violence data collected using social media and digital technologies.

\section{Analysing SMDT data on violent events}

The reliability of data collected during the 'fog of war' or other types of violent crises has always been a major challenge for humanitarian actors, policymakers and academics. This frustration has led some to hope that the 'data revolution' might lift this fog and produce greater clarity about violent events and their underlying mechanisms. However few assessments have been made of the reliability of data collected on violent events using SMDT. To assess the reliability of social media data, we will first evaluate whether this data on violent events is representative of the full scope of violent events, by identifying potential sources of systematic biases in social media data. We will start by looking at the biases that can affect all SMDT-collected data, in particular: (1) biases in geographical and spatial coverage; (2) biases emerging from unequal access and usage of SMDTs by different groups; and (3) biases resulting from social and gender norms. Taking into account that violent events present very specific characteristics, we focus in section 2.4 on biases that result from the nature, characteristics and configurations of violent events, and in section 2.5 on whether SMDTs capture temporal patterns of violent events. We then discuss whether SMDT data is helpful in analysing the social, political and economic mechanisms that trigger and underpin violent events.

During the phase of the 'technology hype cycle' that Gartner (2006) calls the 'peak of inflated expectations' (Figure 1.1), social media was acclaimed as a means to both democratise information flows and to compress time and space (Tsatsou 2009). Social media and digital technologies provide the potential for individuals to publish their own perspectives and to send their own reports immediately, across great distances, to multiple recipients, and at 
relatively low cost. However this potential is not evenly distributed across geographies or demographic groups and, as the next sections will detail, the use of social media and digital technology itself introduces new exclusions and biases that significantly shape data reliability and its utility for analysis of violence and conflict.

\subsection{Geographic and spatial bias in violence reporting}

Not all violent events are equally reported. Reporting of humanitarian crises and violent events by traditional media has historically been subject to geographical imbalances that reflect the financial and power interests of the urban elite over those in the rural periphery (Chan 2017) and the interests of the global North over those of the global South (The Guardian 2015). These geographical inequalities at the local and global level reflect underlying social and political dynamics that privilege coverage of the activities of dominant ethnic, gender and social class groups at the expense of others. For example, during the floods that devastated Thailand in 2011, the north-east region was worst hit in terms of death and destruction; for many weeks its inhabitants were disproportionately left homeless, without food, clean water or sanitation. However media analysis shows that the damage caused to urban businesses in Bangkok and the Central Region received a larger share of media coverage (Chan 2017).

Onto this backdrop the use of social media and digital technology layers new geographical bias, relying as it does on a technical infrastructure that is unevenly distributed both internationally and within individual countries. Internet access is provided via physical fibreoptic or copper cable networks as well as by satellite or cellular networks. These connectivity networks have developed at a faster pace and transmit at greater speeds in the global North than in the global South (ITU 2016). They are also more developed in each country's capital city and commercial centres than in its most remote and rural areas. Internet access and cellular connection are simply not available to many rural populations. This relative inequality exists in many countries that are relatively advanced in economic and technological terms (Chen and Wellman 2004). These geographical inequalities both reflect and reinforce other existing inequalities, and introduce significant biases in data collected through SMDTs. For example in many low-income countries the majority of women live in rural areas. So some women who are already geographically marginalised and living on low incomes also become marginalised in terms of social media participation (Wilson and Gapsiso 2016; A4AI 2017) both as consumers and as producers of social media data.

\subsection{Demographic bias in social media access}

Social media tools such as blogging and microblogging platforms have the advantage of making it possible for an individual to publish their thoughts, perspectives and accounts without professional training or a publishing contract. SMDT potentially provides the means for anyone to independently and autonomously publish on any subject and to reach a potentially wide audience, therefore democratising access to media and voice. However, access to social media and digital technologies is not only geographically uneven but it is also uneven across income, age and other demographic indicators. Therefore, if we rely on social media for violence reporting, many people experiencing violence are structurally silenced whilst the voices of the relatively affluent, urban, young and literate are further privileged (Lerman 2013). If we wish to avoid reproducing and reinforcing existing (dis)advantage it becomes important to understand in some detail the specific ways in which social media and digital technologies exclude. One way of analysing technological exclusions is to use the five 'A's of technology access: Availability, Affordability, Awareness, Ability, and Accessibility (Roberts 2017).

Availability: In most territories a proportion of the population live in remote areas where there is simply no availability of internet or cellular coverage, making access to social media impossible for millions. Commercial pressures mean that internet service providers (ISPs) 
and mobile telecommunications companies invest more heavily in network infrastructure in urban centres when compared to remote communities. It is worth remembering that the majority (60 per cent) of the world's population are not active users of social media; half of the world's population has no internet access, and one third does not own a mobile phone (WeAreSocial 2017). When relying on social media data for violence reporting it is therefore important to conduct an analysis of for whom social media is (un)available.

Affordability: Where there is availability of connectivity infrastructure affordability still excludes another large section of the population from social media use. Affordability acts as a structural constraint on social media use as the cost of a mobile phone handset, as well as call and data credit and battery charging are all significant considerations for low-income groups (Faith 2016) and rural communities. Levels of affluence are a factor in people's ability to use social media. Although affordable access to the internet for everyone by 2020 is one of the United Nations Sustainable Development Goals, the Alliance for Affordable Internet (A4Al) does not expect us to achieve this goal before 2040 (A4Al 2017).

Awareness: Even when social media access is affordable, lack of awareness excludes others from social media use. Some individuals will be unaware of particular violence reporting initiatives, or of particular social media applications, which might be beneficial. While social media companies like Facebook and Twitter spend heavily on marketing to raise awareness of their services, violence reporting initiatives have relatively small or non-existent budgets to raise awareness of their crowdsourcing programmes. Technical investments need to be matched by marketing investments if initiatives are to reach their full potential.

Ability: Among groups that do have awareness of SMDTs, lack of ability still excludes a significant number of citizens from making effective use of the technology as a result of a lack of digital literacy skills (Poveda 2016) or 'informational capabilities' (Gigler 2011). Crowdseeding programmes attempt to overcome the problems of low levels of affordability, awareness, and abilities by carefully selecting informants and providing them with precisely the necessary capabilities and mobile phones to deliver reliable data (Van der Windt and Humphreys 2016). However, our research failed to identify any such initiatives that overcame availability or accessibility.

Accessibility: Even when there is availability, affordability, awareness and ability, issues of accessibility routinely exclude significant numbers from using social media and digital technologies. Some ethnic and linguistic groups are excluded from social media initiatives because the technology only supports particular languages. Social media initiatives of technology interfaces may also lack the adaptive technologies necessary to enable the inclusion of people who are blind or visually impaired for example (ITU 2013). As Hirth et al. (2011) points out: disabled, print illiterate, rural and low-income groups are often systematically under-represented in crowdsourced social media data. 
Figure 2.1 Social media access: the five 'A's

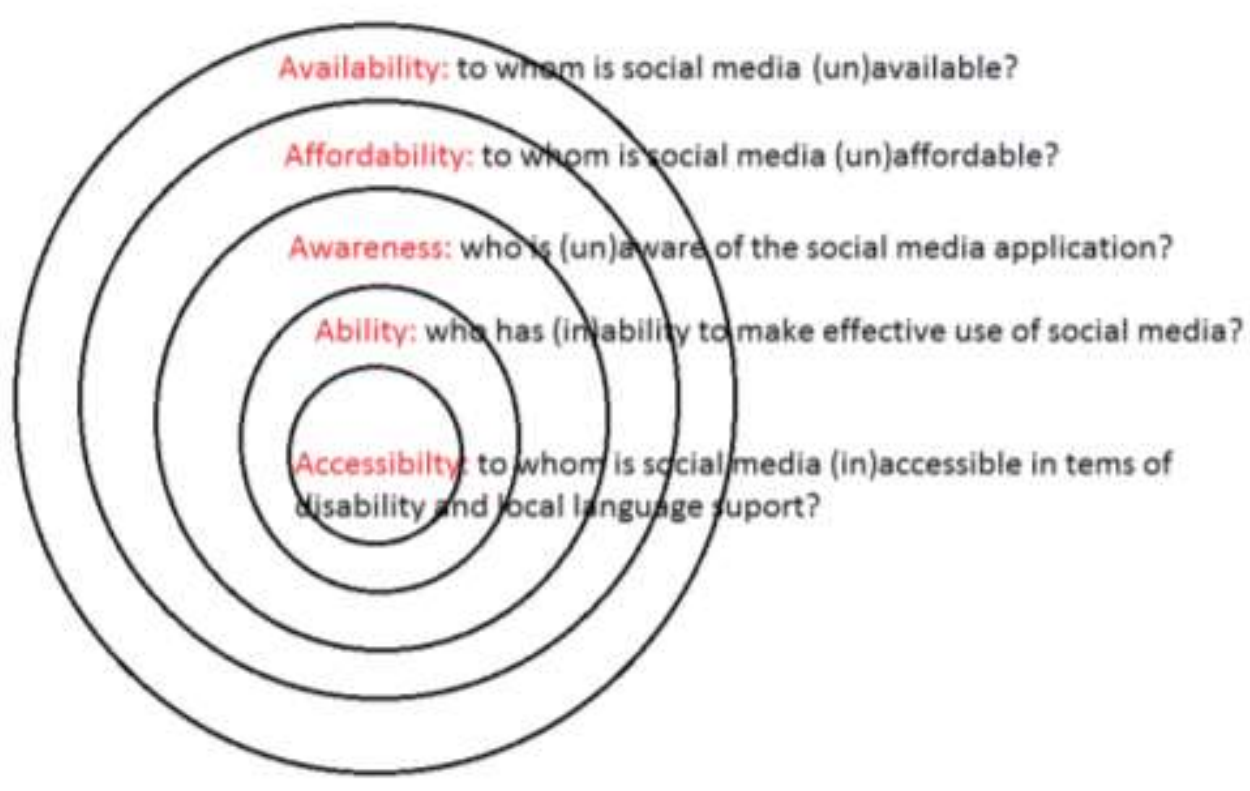

Source: Adapted from Roberts (2017).

Thus, while the rise of social media carried the promise of levelling geographic imbalances and democratising communication, on closer inspection social media does not create a level playing field. Uneven network coverage, asymmetric access to digital devices and lack of skills and awareness all combine to make social media far from a comprehensive source of data. Use of social media in violence reporting is therefore liable to introduce biases including economic class, age and gender, structurally excluding those who cannot or do not upload content on social media.

Although there is always hope that future economic growth and continued technological diffusion will reduce these inequalities, history suggests otherwise. Digital technology has been accompanied by a widening of social inequality and not its reduction (Piketty 2014). This is partly because the already privileged urban, educated, middle class are better placed to exploit its advantages. There are reasons to think that the continued pace of technological change means that low-income groups are likely to lag behind permanently. If rural workers do indeed secure affordable access to the internet by 2040 (defined by A4AI (2017) as access to 1 gigabyte of data for less than 2 per cent of income) we might reasonably expect that by 2040 the urban elite will have upgraded to the next generation of advanced technology and may by then be measuring their internet access in terabytes, thus maintaining their structural advantage.

Even if equality of access to SMDTs could be guaranteed this would be an insufficient condition to guarantee equality of outcomes. The ability of people with access to SMDTs to broadcast their opinion on social media does not mean that they are all equally heard or equally influential. Regular citizens may have several hundreds of Facebook friends or Twitter followers but a politician or celebrity can expect to have millions. The ability to 'capture' attention through content posting is highly dependent on underlying social and class dynamics. In this respect social media tends to amplify existing (dis)advantage rather than create a level playing field. This echoes Toyama's (2011) findings that technology can amplify existing human capacity and intent but that it cannot substitute for it where it does not exist. 


\subsection{Social and gender norms}

Exclusion from the use of mobile phones or social media can also be the result of norms and values that shape unequal social relationships. For example, in Afghanistan social norms often constrain women from public use of mobile phones or social media (USAID 2013). On the other hand the use of a phone can be a valuable means for women to circumvent the restriction of gendered conventions of purdah which restrict women's freedom to travel alone. SMDTs can provide alternative means for women to communicate over distance and to conduct business transactions that obviate the need to travel (Comfort and Dada 2003). In relation to violence reporting, existing gender norms may make individuals unable or unwilling to report violence against women. Domestic violence may be culturally unspeakable or be so commonplace as to be considered not worthy of reporting - resulting in underreporting.

In the Zambian Household Survey, 7,000 women were interviewed about whether a husband was justified in beating his wife if she (a) burnt the food, (b) argued with her husband, (c) neglected the children, or (d) refused to have sex. Sixty two per cent of Zambian women felt that a man was justified in beating his wife in at least one of the situations (ZCSO 2009). This demonstrates how unequal gender norms can be internalised and domestic violence normalised, one consequence of which is that violence against women is under-reported. In Egypt and Morocco, however, women are using social media proactively to report violence against women as part of their wider programme of gender activism. HarrassMap is an Egyptian initiative that enables women to use SMS text messages and social media to generate an online map that geolocates incidents of sexual harassment and violence against women as a tool for organising and advocacy (Peuchaud 2014). In Morocco, WomenShoufouch is a similar SMDT platform used to combat gender-based violence (Skalli 2014). Research indicates that this use of social media has made the scale of violence against women more visible, raised public awareness, and enabled activists to engage powerful stakeholders to press for meaningful change (Peuchaud 2014).

In the Zambian example, cultural norms mean that violence against women is often accepted as normal and goes unreported. In the Egyptian and Moroccan examples, social media is used to actively challenge violence against women. These examples demonstrate how dominant gender norms and gender activism interact with the issues of access from the preceding section. The Afghan example above illustrates how gender norms can restrict the availability of social media to women and the Zambian example shows how gendered norms constrain what is considered to be violence worth reporting. In remote rural areas women's low incomes make smartphones and connectivity less affordable. HarrassMap and WomenShoufouch have built strong networks in urban centres, but in rural areas there is less awareness about such social media initiatives designed to challenge gender norms about violence against women. In rural Zambia boys' education is often prioritised above girls' and these norms affect the abilities to make effective use of SMDT (digital literacy levels). Many of the local languages and dialects used by indigenous communities are not used on social media platforms creating additional accessibility issues. In these ways and others social norms and geographical factors interact with the structural issues of access from the previous section in ways that significantly affect a person's ability to make effective use of social media and digital technologies in violence reporting.

Crowdseeding can be understood as one attempt to redress some of these access issues. Crowdseeding initiatives are proactive in their inclusive recruiting of marginalised groups as active participants in social media-based violence reporting. Crowdseeding initiatives often recruit and train selected informants, and equip and train them to report on violent events. By providing participants with mobile phones, training and phone credit to make calls it is possible to overcome some of the problems of affordability, awareness and abilities and so reduce some of the structural biases of projects that rely on social media data. 
The comparative advantage of crowdseeding platforms is that data collectors can be trained to report specific types of violent events that might otherwise be under-reported, such as rape during war or domestic violence. They can also 'plant' data collectors in particular locations to ensure greater representativeness. Van der Windt and Humphreys (2016) intentionally designed their Voix des Kivus crowdseeding platform to reduce biases due to the positionality of data collectors, or systematic under-reporting of certain types of violent events, in particular violence against women. In each of the villages of the study, they trained three data collectors: one appointed by the village chief (representing traditional authority), one elected by the village, and one representing women's groups. They did not, however, find that women reported more events of violence against women than other reporters. This can point to several underlying mechanisms: either it is a sign that such biases do not exist, or it is a sign that the strategy was not successful in rectifying them. Whilst the Voix des Kivus example is notable in overcoming some of the structural issues of affordability, awareness and ability this example of crowdseeding does not overcome the availability or accessibility issues of the print-disabled or most rural communities.

\subsection{Measurement error due to the nature and characteristics of violent events}

An additional source of potential bias in SMDT data stems from the nature and characteristics of violent events. Violent events differ substantially, and violent episodes often disrupt the contexts in which they occur, which can significantly alter the way data are collected, yet the implications for the reliability of SMDT data on violent events has rarely been analysed.

Nature: Violence constitutes a very large and heterogeneous range of actions (Luckham 2017). How violence is defined, what actions are considered as violent, and what is considered worthy of reporting is socially constructed and changes over time and space. Violence that is considered to have a political character is generally more reported than violence that is considered either criminal or domestic. In the last two decades, there has been a proliferation of projects focused on collecting data on political violence, such as the Armed Conflict and Location and Event Data Project (ACLED), or the Uppsala Conflict Data Program (UCDP). Yet recent analyses of trends of violence on the African continent show that, while armed conflict has receded in recent years, violence related to criminal activity has increased (Aucoin 2017). Criminal violence is tied, in complex ways, to political and social factors, yet data collection projects focused on political violence are not necessarily conceptually and methodologically equipped to collect data on 'non-political' forms of violence. Crime statistics, for example, are usually reported by national states, and are thus dependent on the quality of national statistics agencies. Similarly, domestic violence, which we have previously seen is less likely to be reported because of self-censorship and social norms, is rarely, if at all, considered as political violence and thus much less likely to be picked up by data collection projects. Yet recent studies have shown that that domestic violence increases during episodes of conflict (Wijayatilake and Gunaratne 1999), pointing to much more complex ties between domestic and political violence.

Intensity: Another characteristic of violent events that can affect the way they are reported is their intensity. The intensity of violent events depends on the level of coercive or military means involved, the nature of the violence and the number of people affected by it. The relationship between the intensity of violent events and their reporting using SMDT, however, is not linear. On one hand, higher-intensity violent events, involving more brutal forms of violence or higher numbers of victims, can be more 'visible' and therefore more likely to be witnessed and reported on SMDT systems. High-visibility violent events such as bombings or mass killings are more likely to be reported than systematic and normalised violence which may be more extensive but less intensive. Intensity may, in certain cases, offset the effects of low phone or internet coverage (Dafoe and Lyall 2015: 404). On the other hand, highintensity violent events can also have a negative effect on the level and accuracy of reporting through SMDTs. The destruction of telecommunications infrastructure, forced migration due 
to combat, fear of reprisals, physical and psychological distress may mitigate against SMDT reporting. In extreme cases, high fatalities mean that there might not be anyone left alive around to witness or report the violence (De Juan and Bank 2015 Appendix 1: 1).

Configuration and complexity: The configuration of violent events and their complexity can also affect the accuracy of reporting. In armed conflicts, the larger the number of military actors involved in a battle, the more difficult it is to identify different actors and to attribute violent events to specific actors. Higher numbers of protagonists and actions also raise the likelihood that measurement error will occur due to the complexity of the event and resulting confusion. Analysing media coverage, Weidmann (2015) shows that measurement error for location and casualty reporting is less accurate for battles involving a large array of actors than for one-sided attacks. Given their reliance on non-professional data collectors, similar measurement errors are likely to be present in SMDT data as well, although their magnitude has not yet been evaluated.

It is worth noting that military configurations can reflect and amplify the geographical imbalances in media coverage previously discussed, as geography is a key dimension of military strategy and the distribution of military resources, particularly in civil wars. A typical civil war configuration is one where the government holds cities and larger towns as well as strategic outposts and routes, while rebel factions set up base in remote and difficult to access areas such as forests, mountains, or islands - regions that often have reduced phone coverage. This military configuration closely reflects internet and phone network coverage as both are dependent on geography: as a result, geographical reporting biases can generate or amplify organisational reporting biases. For example, Weidmann (2015) shows that only 30 per cent of the violent events present in the USA's 'Significant Activities' military database that are coded as perpetrated by insurgent groups were present in media-based data sets, a very large discrepancy that points to potentially large biases in media-based data, which could also be present in SMDT data.

It is also important to note that a protagonist's military dominance may give them the ability to control, distort or censor social media platforms and even to entirely cut off their availability to opposition forces. Blocking access to social media platforms has become a widespread tool of political repression, used for example in Burundi in 2015, or in DRC in December 2016 to quell the mobilisation against President Kabila's refusal to step down after the end of his constitutional mandate (Reuters 2016). As a result, SMDT coverage of an event might be extensive for a certain period and then severely reduced following repressive measures, which can lead to unbalanced event coverage that cripples data analysis. Furthermore, state intelligence agencies both passively monitor mobile phone and social media traffic as well as employing assets to actively influence online content. The United Kingdom (UK) army reportedly recruits soldiers with social media skills for its $77^{\text {th }}$ Brigade to run 'non-lethal operations' (MacAskill 2015). The increased investment of protagonists in efforts to influence social media discourse and to distort it with 'fake news', raises new validity and verification challenges about how those interpreting SMDT reports on violence can discern information from disinformation.

Not all actors in a violent conflict have the power to block social media platforms or shut down the internet, but other tactics may be deployed to repress the use of social media. Close control and monitoring of the use of digital technology by civilian populations is another mode of operation. It usually requires developing a significant political repression apparatus and deeply infiltrating social networks. This has been the case in Mexico, where the drug cartels systematically target and assassinate those suspected of reporting violent events on social media platforms such as the Blog Del Narco (Monroy-Hernandez and Palacios 2014). Such monitoring of social media usage can lead to distortion of reporting of violent conflict. In major battles, such as the battle for Mosul in Iraq in 2016-17, access and usage of social media might be thoroughly repressed on one side and encouraged on the other, leading to unbalanced reporting. 
Temporality: Another key dimension of violent events is their temporality, which refers to the way they unfold over time. Along with geographical and spatial patterns of violent events, temporality is key to understand the diffusion of violent events. Given that one of the comparative advantages of SMDT data is the capacity to record events in real-time, the question of whether SMDT data can accurately capture the temporality of violent events requires a more extensive discussion.

Despite the centrality of temporality and diffusion in understanding patterns of violent events, few studies to date pay specific attention to them (Bruck et al. 2015: 35). As Van der Windt and Humphreys (2016) note, studies of conflict diffusion have long been focused on international cross-national conflicts (Braithwaite 2010; Buhaug 2008). Recently, however, a stream of literature has paid increased attention to the micro-spatial and micro-temporal dynamics of conflict diffusion (Schutte and Weidmann 2011), using novel data collection methodologies partially based on digital technologies, such as the geospatial location of conflict events based on interviews (Mc Doom 2013), or novel violent event location datasets based on media reporting such as ACLED (Dowd and Drury 2017).

Temporality is not only key in explaining the diffusion of violence, but also in capturing the change in both the causes and consequences of violence, which can have a dynamic character: variables that might have a causal effect on violence at one point in time might not do so at another point. Recent advances in survey methods have allowed researchers to move beyond cross-section type data, which cannot capture the temporal dimensions of violent events as they are limited to a single point in time. In particular, recall methods, where respondents are asked to recall the value of a variable in the past, allow the building of retrospective panel data sets, which are data sets where the value of one variable is recorded at different points in time. This enables an analysis of the change in the value of variables over time, and has recently been applied to the analysis of violent events and armed conflict (Bruck et al. 2015; Sanchez de la Sierra 2017; Marchais 2016; Justino and Stojetz, forthcoming). However, the accuracy and reliability of retrospective panel datasets can be affected by recall bias, which results from the errors respondents make in recalling past events. Studies assessing the quality of data collected through recall methods have shown that the means of variables can be recalled accurately, but that the variation of the value of variables is prone to significant recall error (De Nicola and Gine 2014: 53). Thus, while this type of data is reliable to assess broad temporal trends on key variables, it cannot allow a fine-grained analysis of small scale temporal variations in these variables. Given the speed at which violent events occur and their complexity, this constitutes a severe limitation of such data.

SMDT data can address these fundamental limitations, as the data are generated and collected in real-time, and each piece of data is automatically geolocated and date-stamped, allowing researchers to capture spatial and temporal diffusion of violent events with increased precision. This can significantly reduce recall and measurement error and thus produce more reliable time-series data sets. Comparing data collected through their Voix des Kivus crowdseeding platform and data from a previous survey they implemented in the province of South Kivu, DRC, Van der Windt and Humphreys (2016) show that survey-based data can lead to conclusions that are opposed to those found using fine-grained near-realtime data, illustrating the comparative strength and promise of these methods. Big data approaches can also increase capacity to capture timing and temporality of violent events, as they can provide extensive and very fine-grained data, particularly in areas with high mobile phone and internet coverage, such as cities (Unver and Alasaad 2016).

Yet not all SMDT data collection methods display similar capacities to accurately capture the timing of violent events. Comparing data obtained through crowdsourcing platforms (in particular the Syria Tracker) and non-SMDT based reports on violent events in Syria, Price et al. (2013) and De Juan and Bank (2015) find high correlation factors on dates and timing, 
suggesting such platforms accurately capture the timing of violent events. De Juan and Bank (2015) and Masad (2013), however, find significant temporal discrepancies between violent events reported in the Syria Tracker and those reported in the Global Data on Events, Location and Tone (GDELT) data set, which is based on news reports from international news sources (De Juan and Bank 2015 Appendix 1: 3). According to them, this is most likely due to time lags between the reporting of violent events on crowdsourcing platforms and their reporting in international news outlets. The causes of these temporal discrepancies are not clear but may include delays in translation of events reported in different languages. Given that crowdsourcing platforms rely on volunteers that are usually present in the areas where the violence occurs, the lags in reporting could also be due to factors such as displacement or lack of access to internet. They could also be due to short-term recall bias in the reporting of dates and times of events, which is likely in situations of distress and trauma. As a result of these temporal discrepancies, De Juan and Bank suggest that the Syrian Tracker should be used to analyse the spatial patterns of violent events rather than their temporal patterns. The temporal accuracy of SMDT data collection should therefore not be taken for granted, and the temporal measurement error systematically evaluated.

The issue of temporality of SMDT data is also tied to the core questions of causality and causal inference. While causal inference is fundamentally an academic question, this issue concerns all uses of SMDT data collected for purposes that are not strictly descriptive (such as locating violent events) and imply conjectures about causality. Dafoe and Lyall (2015) identify the core problem as one of dependence resulting from the temporal and spatial structure of SMDT data sets, where observations do not satisfy the core requirement of independence, which is necessary for causal inference (Dafoe and Lyall 2015: 407). For example, when estimating whether violence (dependent variable) increases as a result of mobile phone coverage and access to social media platforms (independent variables), time can affect both the outcome variable and the independent variable, but also be altered by the independent variable, as access and usage of SMDT technologies changes the temporal and spatial dynamics of violence. According to Dafoe and Lyall (2015: 403), 'this is especially true for ICTs which tend to influence politics through their amplification and suppression of other processes related to communication, coordination, and monitoring'. While this issue can be partially mitigated through corrective statistical measures, it is not just a statistical question, and touches the very core of the assumptions that underpin the use of SMDT data, and the core assumptions about violent events. What is required, therefore, is a better understanding of the underlying causal processes underpinning the usage of such methods in conflictaffected settings, and the ways these might influence violent events and reporting biases. This calls for complementary in-depth qualitative research on the mechanisms of violence, and the mechanisms through which the use of ICTs might affect both the temporal dimensions of violence and its reporting (Dafoe and Lyall 2015: 402).

\subsection{Capturing underlying mechanisms of violence}

In addition to the fundamental question of temporality, it is important to assess whether SMDT data can accurately capture the mechanisms that underpin violent events. Violent events are co-determined by a range of complex social, economic and political processes that precede them and enable their diffusion (Wood 2003, 2008; Kalyvas 2006). One of the risks of using SMDT to study violent events is to direct attention away from the underlying causes. Initial analyses of the Arab Spring, for example, presented it as a 'Facebook revolution'. This foregrounding of social media as a determinant of social change was at the expense of a deeper analysis of the social and political determinants. Recent in-depth and empirically grounded studies of the revolutionary movement in Egypt have challenged the dominant narrative that the protests were spearheaded by liberal-minded, secular youth seeking to challenge the long-standing autocratic regime and the conservative religious social order. These studies show that social media played an important role, relaying calls to protest, sharing protest tactics, and documenting events, but it was the mosques and religious brotherhoods, which were deeply embedded in urban neighbourhoods that enabled 
the bulk of the mobilisation and its persistence over time (Eghdamian 2014; Hofmann and Jamal 2014; Ketchley 2016). These studies also show that the protests were violent from their onset, with protesters systematically targeting symbols of state repression, in particular police stations (Ketchley 2016). What this example points to is the need to complement an analysis of SMDT data with in-depth understanding of the mechanisms that underpin violent events, and the necessity of careful triangulation of sources.

When used appropriately, recourse to SMDT data can enable an analysis of these underlying dynamics that would be extremely difficult to carry out using traditional data. In their analysis of the 2015 anti-coup mobilisation in Turkey, Unver and Alasaad (2016) used an algorithm they developed to 'comb' social media in real time and generate fine-grained temporal and spatial data on dynamics of mobilisation. This allowed them to prove that the bulk of the anticoup mobilisation could be traced back to early mobilising efforts by Istanbul's traditional networks, organised around mosques and neighbourhoods. Contrary to what had been widely reported in international media, it was not the result of Erdogan's media appearances and calls to mobilise, which they show occurred after the bulk of the popular mobilisation. The mosques mobilised through traditional methods - salah prayers - combined with an extensive use of SMS and social media (Unver and Alasaad 2016). It is the overlap of these mobilisation methods, they show, that explains the strength and intensity of anti-coup mobilisation. The analysis of SMDT data must therefore be combined with a close understanding of the social processes that underpin violent events.

Furthermore, the content of SMDT data can reveal aspects of violent events that cannot be captured by traditional media. The Forensic Architecture project Forensis, based at Goldsmith's University in London, uses social media content to generate dynamic 3D modelling of violent events and their architectural environment. ${ }^{1}$ As a large number of armed conflicts take place in dense urban settings, the architecture of these urban centres becomes a key dimension of combat and violence. These urban environments are often well covered by social media and densely populated, which generates very dense social media content that can be compiled and triangulated to reproduce the sequencing of events, but also provide a visualisation of their unfolding in space and in particular architectural settings. The Forensis project used such methods to build 3D reconstitutions of, among other violent episodes, the airstrike on the M2 hospital in Aleppo in 2016, or the use of white phosphorus bombs by the Israeli army in the Gaza strip during Operation Cast Lead in 2008-09. As they are based on primary social media data, these reconstructions are then presented as evidence for international prosecution teams, NGOs and other policy actors working on violent crimes.

In this section, we have reviewed several aspects that are crucial in assessing the reliability of SMDT data for reporting and analysing violent events. We have seen in particular that, for all its promises, SMDT data can be affected by a range of biases that can affect their representativeness (Tufekci 2014). This does not mean that social media data have no value. All data sources contain bias. What is important is that those monitoring and analysing data are mindful of the particular biases of each data set and triangulate with alternative data sets that are complementary. When this is done with appropriate rigour, social media data can add micro-level detail not available by other means and it can make these data available in near real-time. 


\section{Beyond data collation}

The majority of the existing literature on the use of SMDTs in violence reporting and analysis has focused on describing the technology and data collation process. Relatively little analysis exists on translating data into actionable information and the extent to which this has led to change. This section will begin by presenting practical examples work that go beyond technology description and address how to produce data that are actionable by social change agents. The following section will then present some findings on the comparative (dis)advantages of different SMDTs compared to traditional methods. Finally, we will assess some of the ethical considerations raised by using SMDTs in violence reporting and analysis before concluding with some tentative recommendations.

\subsection{Towards actionable data}

Some social media and digital technology initiatives go beyond capturing violence data and are specifically designed to facilitate practical action by peace activists or policy actors. Increasing efforts are being made to tailor data monitoring processes to produce actionable information that has the potential in the prevention, de-escalation or mitigation of violence. At a community level, PeaceTXT ${ }^{2}$ is one such initiative that works with existing neighbourhood peace groups in the United States and Kenya; they apply mobile tools to amplify and extend the reach of the organisation's existing awareness-raising methods. Developed in partnership with New York University, E-Responder has developed an evidence-based approach to assessing the impact of their mobile phone-based approach in which they equip anti-violence professionals with the technical abilities and intervention skills to track, identify, and de-escalate online conflicts before they spill over into offline conflict. Their research shows that increasingly, the 'virtual' violence that starts online can turn real physical assaults and deaths (Javdani 2017). One of the advantages of real-time social media monitoring like this is that it raises the possibility of recognising rising tensions early and acting in a timely manner. Social media monitoring tools offer the potential to monitor escalating tensions, and, where early identification is successful, it creates the opportunity to launch de-escalation interventions along the lines of E-Responder and PeaceTXT.

The ability to crowdsource millions of social media reports and to conduct keyword analysis in real-time makes it possible to track developing tensions, hate speech and threats online. As social media reports contain metadata that can include precise geographical location and the time of posting, it is possible to generate an online 'heat map' of rising tensions over time which can be used to trigger peace-keeping responses and violence de-escalation measures. The challenge however is that whilst keyword data filtering can be automated and performed in near real-time, the task of interpreting data contextually and making judgements about appropriate responses is an essentially human task. Therefore bringing the right human capacity to bear on what may well be life-and-death decisions is key. Sambuli et al. (2013) and Moreno et al. (2017) have provided some insight into the combination of actors it is necessary to bring together in a live social media monitoring 'situation room' as well as the various practical stages between data collection and producing actionable data to emergency services and other actors.

Election monitoring is used here as an example of producing actionable data from social media reports. Social media monitoring of election violence has taken place in many countries worldwide including Kenya (Makinen and Wanu Kuira 2008), Nigeria (Bartlett et al. 2015), Sri Lanka (CMEV 2015) and Ghana (Moreno et al. 2017). One passive crowdsourcing initiative collected 13 million individual posts in Twitter (called 'tweets') posted by 1.3 million unique users, including 408,000 tweets about election violence (Bartlett et al. 2015). Using a combination of automated filtering and manual data analysis, researchers were able to

$2 \quad$ https://poptech.org/peacetxt 
segment the data by geographic and demographic categories contained in the metadata for each tweet time and map and visualise the data online. This passive surveillance of big data from Twitter enables analysis to draw on a huge number of individual reports that make it possible to discern patterns and trends (spatial and temporal correlates) not available by other means. At the same time it is possible to drill down to the granular level of each individual first-person report and their precise location. One of the challenges of social media's open interface, however, is that individuals are free to exaggerate, purposefully distort, or be mistaken in their reports. Unlike professional reporting protocols of mainstream media there is no built in verification mechanism on social media - so election monitoring programmes need to establish their own verification processes.

Moreno et al. (2017) describe a Social Media Tracking Centre, which was used to monitor for violence during elections in Ghana using a social media aggregator platform called 'Aggie'. The centre was staffed by local civil society organisations and volunteers who were divided in a tracking team, a veracity team, an escalation team, and an embedded team. The job of the tracking team is to monitor reports generated automatically by Aggie and to identify relevant actionable issues. They then produce 'incident reports' containing verifiable information, such as the time and location of the incident and the actors involved. The veracity team then have the job of checking the incident details as well as corroborating the story with third parties. Verified incident reports are then passed to the escalation team for communication to, and coordination with, front-line response organisations. The embedded team are based within partner organisations and can support them in taking appropriate action. This illustrates the importance of investing in human resources and skills to contextualise, interpret and verify social media data before it is actionable.

In a separate study of Kenya's 2013 elections Sambuli et al. (2013) provide a unique comparative analysis of passive and active crowdsourcing with traditional media. Mainstream media monitoring was compared both with passive Twitter crowdsourcing using the proprietary Dataswift application, as well as with the active crowdsourcing using the Ushahidi-based election platform called Uchaguzi. In their passive crowdsourcing process, Twitter data mined from the Twitter API were cleaned and processed by a technical team of specialists using machine learning technology. In their active crowdsourcing process, a team of election observers located at polling stations were used to verify reports and a team of online and local volunteers reviewed citizens' reports and organised them into structured workflows. Like the Ghanaian example, this also points to the importance of contextual analysis and the need to invest in human interpretation of data. What emerges from analysing these different approaches is that each method has its strengths and weaknesses. When taken together with the analysis from earlier sections it becomes possible to tabulate these comparative (dis)advantages. 
Table 3.1 Comparative (dis)advantages of violence reporting media

\begin{tabular}{|c|c|c|}
\hline & Advantages & Disadvantages \\
\hline $\begin{array}{l}\text { Passive } \\
\text { crowdsourcing }\end{array}$ & $\begin{array}{l}\text { Huge volumes of free data } \\
\text { Automated filtering } \\
\text { Filtering terms modifiable } \\
\text { Generates most incident reports }\end{array}$ & $\begin{array}{l}\text { Impossible to verify in real time } \\
\text { No informed consent } \\
\text { High noise/signal ratio } \\
\text { Time-consuming to process } \\
\text { Likely to contain disinformation } \\
\text { Needs highly specialised staff }\end{array}$ \\
\hline Active crowdsourcing & $\begin{array}{l}\text { More targeted } \\
\text { Lower data volume to process } \\
\text { Easier to verify in real time }\end{array}$ & $\begin{array}{l}\text { Subject must be pre-determined } \\
\text { Generate less incidents than } \\
\text { passive } \\
\text { Needs specialised }\end{array}$ \\
\hline Crowdseeding & $\begin{array}{l}\text { Targeted } \\
\text { Trained data collectors } \\
\text { Community participation }\end{array}$ & $\begin{array}{l}\text { Subject must be pre-defined } \\
\text { Only works in defined area } \\
\text { Expenses of training and equipping }\end{array}$ \\
\hline Traditional media & $\begin{array}{l}\text { Targeted } \\
\text { Trained reporters } \\
\text { Rigorous verification protocols } \\
\text { Can operate in remote areas } \\
\text { without phone/internet coverage }\end{array}$ & $\begin{array}{l}\text { Labour-intensive } \\
\text { Expensive trained journalists }\end{array}$ \\
\hline
\end{tabular}

Source: Authors' own.

Access to social media data streams has an economic dimension. Whilst many social media monitoring projects use the free Twitter Streaming API and researchers can access historical data freely using the Twitter Search API in order to access the unlimited access of the full Twitter or Facebook 'firehose' of data fees are payable. ${ }^{3}$ This raises a new dimension of affordability as full data access is only available to those with the ability to pay for the data and for the significant associated cost of human interpretation of that data. When users of social media platform sign up to the terms and conditions they are often unaware that their data will become available as a commodity that is tradable in these ways, raising ethical issues, which are the subject of the next section.

\subsection{Ethical challenges of social media data use}

Using crowdsourced data presents significant ethical challenges. Ensuring that we 'do no harm' requires careful consideration and local contextual knowledge as the potential exists to expose data collectors or data originators to violence or repression as the following examples illustrate.

Mainstream journalists and reporters are often subjected to violence or political repression in contexts of violent conflict. Risks associated with exposing the actions of powerful protagonists in militarised contexts do not disappear because the medium is now SMDTs. Citizen journalists providing microblogging and blogging content on social media platforms like Raqqa is Being Silently Slaughtered (Orton 2015) or Blog Del Narco (Carroll 2013) were physically attacked and in some cases tortured and executed by the insurgents and cartels that they reported on. In Moscow, social media reporters have been imprisoned. In Paris,

3 For a more detailed explanation see: https://brightplanet.com/2013/06/twitter-firehose-vs-twitter-api-whats-the-differenceand-why-should-you-care/ 
citizen journalists filming police have been beaten. Each example testifies to the potential for recrimination and violence against social media reporters. Crowdsourcing platforms are normally geographically removed from the sites of violence, often in foreign and relatively 'safe' countries, ${ }^{4}$ while risk resides primarily with in-country reporters or networks of reporters. Actions taken by crowdsourcing platform operators can directly influence the level of risk these reporters face, such as unintentionally revealing reporters' location or identity.

Although the situation of war reporting is an extreme case, it raises significant ethical issues that pertain in other uses of social media data and which may expose individuals to threats, violence, repression or manipulation. Oxfam are amongst an international consortium who have developed a rights-based approach to responsible data management (O'Donnell 2015). As local staff and community members on the ground are the experts in any specific context, the responsible data policy firstly ensures that those on the frontline inform and own the process. This approach includes, but goes beyond, data encryption to involve communities in the process of data collection and usage without inadvertently putting people at risk. The policy affords the right to privacy and not to be put at risk, but also the positive freedoms to be heard and respected and to be able to make informed decisions (Oxfam 2015).

In humanitarian and academic work informed consent is a requirement, prior to collection of data on human subjects. In crowdseeding and active crowdsourcing that involves a call-toaction it is possible that appointed data collectors can be informed about the uses to which data may be put and their consent sought. In the Voix des Kivus project, this was done by organising a village-wide meeting to present the data collection process for discussion and adoption. This, however, raises the issue of the anonymity of data collectors, as revealing their identity can potentially expose them to increased censorship, pressure, coercion or violence. In the case of passive crowdsourcing, the automated filtering process can potentially anonymise the identity of reporters but obviates the opportunity for informed consent.

Another central ethical issue concerns the autonomy and independence of data collection that relies on social media and digital technologies. Information is a weapon of war. TV and radio stations have always been primary military targets and the same may now be true of social media channels. As the Blog del Narco and Raqqa examples above illustrate, protagonists may exact violence on social media journalists in pursuance of military objectives. There is also evidence that state and non-state actors are investing in 'armies' of human and robotic actors in order to influence online narratives (The Guardian 2016). Powerful actors in violent conflicts have the ability to attack, threaten or co-opt individual media outlets. The most powerful actors may also have the means to block access to particular online platforms and in extreme situations to shut down local access to the internet altogether. The autonomy and independence of social media is then a particular issue in active conflict zones where powerful military and political actors are involved.

International NGOs are notoriously easy to infiltrate by state intelligence services, which can use them as covers to gather intelligence on conflict-affected areas. Therefore, the collection of social media data by NGOs may expose citizens to risk and pose difficult questions about data protection and access. Powerful corporations also have the power to shut down social media channels. One example of this is Apple's banning of Metadata+, a mobile app that aggregates journalist reports of deaths caused by US drone strikes in Pakistan, Yemen and Somalia, all countries that the USA is not at war with. Metadata+ creates a record of deaths not covered by mainstream media through a dedicated social media channel. Apple initially refused to list the app under its original name of Drones+ and then later removed Metadata+ app from the Apple iStore on the grounds that it contained 'objectionable' data. Metadata+, however, remains available on Android phones. 


\subsection{Concluding remarks and recommendations}

This paper has focused on the increasing role of social media and digital technologies in the rapidly changing landscape of violence reporting and analysis. Social media and digital technologies allow those monitoring violence access to a wealth of new data that is largely free and machine readable. This opens the possibility to automatically filter millions of reports to reveal patterns and trends at the macro level, at the same time as drilling down to individual first-person reports which are date- and time-stamped. This enables forms of analysis and insight not available by other means and secures a valuable role for SMDTs among other violence reporting media.

This paper has identified and categorised different types of SMDTs and presented some of their comparative advantages and disadvantages in relation to each other as well as in relation to more traditional media. This contribution is intended to help activists, policy actors and researchers to select SMDTs and to blend them with traditional means in complementary ways.

Importantly, this paper has also drawn specific attention to the particular biases and risks that the use of SMDTs introduce or accentuate. Sixty per cent of the global population are not users of social media - so any reporting or analysis that relies on SMDT has the unintended consequence of structurally silencing 'those who do not tweet' due to their lack of availability, affordability, awareness, abilities or accessibility to SMDTs. These exclusions are non-trivial as marginalised people are often among those worst affected by violent conflict as well as the most challenging to reach. It is sometimes assumed that over time these challenges will disappear as rising levels of economic growth will extend the provision of technical infrastructure and so remove the kind of biases highlighted in this report.

However, evidence does not support this linear logic. Digital divides and unequal gender norms persist even in those economies with the highest levels of technological adoption. This suggests that there is a need for more targeted interventions in excluded and marginalised communities as well as for digital development interventions that consciously design for equity from the outset. Furthermore, the paper has discussed the comparative strengths and limitations of using SMDT data with regards to accurately capturing the processes and mechanisms that underpin violent events, with particular attention to temporality and spatial patterns. We have shown that, while using SMDTs can bring significant advantages when compared to traditional data sources and media, they are also prone to a range of biases that can affect the understanding of these violent events. Finally, we have shown that collecting and analysing data in conflict-affected contexts generates significant logistical and ethical challenges, tied to the fact that, as any source of information in such contexts, SMDT data is subject to manipulation and falsification. We conclude that it is crucial that social media and digital technologies are used critically.

The main recommendations arising out of this study reflect this:

- $\quad$ Social media data need to be complemented by data from other sources. This is necessary to avoid the risk of amplifying the existing advantage of the already privileged as well as the disadvantage of the digitally excluded.

- Investments in technology must be matched by investments in the human capacity to verify and validate social media data. Crowdsourced data require translation and interpretation in order to produce actionable data and new knowledge.

- Critical and contextual analysis is necessary to avoid superficial description and to pinpoint the causes of violence. One of the risks of using SMDTs to study violent events is to direct attention toward description of violent events rather than their causes. We therefore recommend that data analysis is complemented with critical and 
contextual analysis to identify and direct attention toward the root causes of violence. Furthermore, given that significant biases can emerge with regards to spatial distribution and temporal accuracy, we recommend that a careful analysis of the spatial and temporal dynamics of the studied violent events is also carried out.

- Policy measures should focus on the five A's to remove existing structural barriers to technology access. Rural connectivity programmes could target lack of availability. Competition regulation could target the barrier of affordability. Public information campaigns could improve awareness of key initiatives. Training provision could address missing abilities, and adaptive technologies for those living with disabilities can address accessibility barriers. 


\section{References}

A4AI (2017) 2017 Affordability Report, Washington DC: Alliance for Affordable Internet

Amnesty International (2006) Beyond Abu Ghraib: Detention and Torture in Iraq, Research Report, www.amnesty.org/en/documents/mde14/001/2006/en/(accessed 5 May 2017)

Aucoin, C. (2017) 'Less Armed Conflict but More Political Violence in Africa', Institute for Security Studies, 12 April, https://issafrica.org/iss-today/less-armed-conflict-but-morepolitical-violence-in-africa (accessed 5 May 2017)

Bartlett, J.; Krasodomski, A.; Jones Nengak, D.; Fisher, A. and Jesperson, S. (2015) Social Media for Election Communication and Monitoring in Nigeria, London: Demos

Baum, M.A. and Zhukov, Y. (2015) 'Filtering Revolution: Reporting Bias in International Newspaper Coverage of the Libyan Civil War', Journal of Peace Research 52.3: 352-68

Blattman, C. and Miguel, E. (2010) 'Civil War', Journal of Economic Literature 48.1: 3-57

Boyd, D. and Crawford, K. (2011) 'Six Provocations for Big Data', paper presented at the symposium 'A Decade in Internet Time: Symposium on the Dynamics of the Internet and Society', University of Oxford, September 2011, https://ssrn.com/abstract=1926431 (accessed 5 May 2017)

Braithwaite, A. (2010) 'Resisting Infection: How State Capacity Conditions Conflict Contagion', Journal of Peace Research 47.3: 311-19

Bruck, T.; Justino, P.; Verwimp, P. and Avdeenko, A. (2015) 'Measuring Violent Conflict in Micro-level Surveys: Current Practices and Methodological Challenges', The World Bank Research Observer 31: 29-58

Buhaug, H. (2008) 'Contagion or Confusion? Why Conflicts Cluster in Space', International Studies Quarterly 52.2: 215-33

Carroll, R. (2013) 'Blog del Narco: Author who Chronicled Mexico's Drugs War Forced to Flee', The Guardian, 16 May, www.theguardian.com/world/2013/may/16/blog-delnarco-mexico-drug-war (accessed 5 May 2017)

Chan, E. (2017) Public Health Humanitarian Response to Natural Disasters, London: Routledge

Chen, W. and Wellman, B. (2004) 'The Global Digital Divide: Within and Between Countries', IT \& Society 1.7: 39-45

CMEV (2015) Final Report on Election Related Violence, Colombo: Centre for Monitoring of Election Violence, https://cmev.org/category/final-reports/(accessed 5 May 2017)

Comfort, K. and Dada, J. (2003) 'Rural Women's Use of Cell Phones to Meet their Communication Needs: A Study from Northern Nigeria', in I. Buskens and A. Webb (eds), African Women and ICTs, London: Zed Books

Dafoe, A. and Lyall, J. (2015) 'From Cell Phones to Conflict? Reflections on the Emerging ICT-Political Conflict Research Agenda', Journal of Peace Research 52.3: 401-13 
De Juan, A. and Bank, A. (2015) 'The Ba'athist Blackout? Selective Goods Provision and Political Violence in the Syrian Civil War', Journal of Peace Research 52.1: 91-104

De Nicola, F. and Gine, X. (2014) 'How Accurate are Recall Data? Evidence from Coastal India', Journal of Development Economics 106: 52-65

Dowd, C. and Drury, A. (2017) 'Marginalization, Insurgency and Civilian Insecurity: Boko Haram and the Lord's Resistance Army', Peacebuilding 5.2: 136-52

Earl, J.; McKeeHurwitz, H.; Mejia Mesinas, A.; Tolan, M. and Arlotti, A. (2013) 'THIS PROTEST WILL BE TWEETED: Twitter and Protest Policing during the Pittsburg G20', Information, Communication and Society 16.4: 459-78

Eghdamian, K. (2014) 'What was the Role of Religion in the Arab Spring?' Open Democracy, 28 July, www.opendemocracy.net/arab-awakening/kat-eghdamian/what-was-role-ofreligion-in-arab-spring (accessed 5 May 2017)

Faith, R. (2016) 'How Does the Use of Mobile Phones by 16-24 Year Old Socially Excluded Women Affect their Capabilities?', unpublished PhD thesis, The Open University

Gao, H.; Barbier, G. and Goolsby, R. (2011) 'Harnessing the Crowdsourcing Power of Social Media for Disaster Relief', IEEE Intelligent Systems 26.9

Gartner (2006) ‘Gartner Hype Cycle: Interpreting Technology Hype’, www.gartner.com/ technology/research/methodologies/hype-cycle.jsp (accessed 29 April 2017)

Gigler, B.S. (2011) Informational Capabilities: The Missing Link for the Impact of ICT on Development, E-Transform Knowledge Platform Working Paper 1, Washington DC: World Bank

Heeks, R. (2009) The ICT4D 2.0 Manifesto, Manchester: IDPM

Hirth, H.; Hossfeld, T. and Tran-Gia, P. (2011), Human Cloud as Emerging Internet Application: Anatomy of the Microworkers Crowdsourcing Platform, Research Report 478, University of Wuerzburg

Hofmann, M. and Jamal, A. (2014) 'How Islam Mattered in the Arab Uprisings, The Washington Post: The Monkey Cage, 17 July, www.washingtonpost.com/news/monkey-cage/wp/2014/07/17/how-islam-mattered-inthe-arab-uprisings/?utm term=.f23698a873f8 (accessed 5 May 2017)

International Telecommunications Union (2016) ICT Facts and Figures 2016, Geneva, International Telecommunications Union

International Telecommunications Union (2013) The ICT Opportunity for a Disability-Inclusive Development Framework, Geneva: International Telecommunications Union

International Telecommunications Union (2010) ICT as an Enabler for Smart Water Management, Geneva: International Telecommunications Unit

Javdani, S. (2017) 'E-Responder Aims to Stop Real World Violence That Start Online', New York University, http://steinhardt.nyu.edu/site/ataglance/2017/02/e-responderdeveloped-by-the-citizens-crime-commission-and-nyu-steinhardt-aims-to-stop-realworld-violence-that-starts-online.html (accessed 20 March 2017) 
Justino, P. and Stojetz, W. (forthcoming) On the Legacies of Wartime Governance, Households in Conflict Working Paper Series

Kalyvas, S. (2006) The Logic of Violence in Civil War, Cambridge: Cambridge University Press

Ketchley, N. (2016) Egypt in a Time of Revolution, Cambridge: Cambridge University Press

Kleine, D. (2013) Technologies of Choice? ICTs, Development and the Capabilities Approach, Massachusetts MA: MIT Press

Kraemer, K.L.; Sharma, P. and Dedrick, J. (2009) 'One Laptop Per Child: Vision vs. Reality', Communications of the ACM 52.6: 66-73

Lerman, J. (2013) 'Big Data and its Exclusions', Stanford Law Review, www.stanfordlawreview.org/online/privacy-and-big-data-big-data-and-its-exclusions/ (accessed 20 March 2017)

Luckham, R. (2017) 'Whose Violence, Whose Security? Can Violence Reduction and Security Work for Poor, Excluded and Vulnerable People?', Peacebuilding 5.2: 99-117

MacAskill, E. (2015) 'British Army Creates a Team of Facebook Warriors', The Guardian, 31 January, www.theguardian.com/uk-news/2015/jan/31/british-army-facebookwarriors-77th-brigade (accessed 27 April 2017)

Madianou, M.; Longboan, L. and Ong, J. (2015) 'Finding a Voice through Humanitarian Technologies? Communication Technologies and Participation in Disaster Recovery', International Journal of Communication 9:3020-38

Makinen, M. and Wangu Kuira, M. (2008) 'Social Media and Postelection Crisis in Kenya', Information and Communication Technology - Africa 13

Marchais, G. (2016) 'He Who Takes the Weapon Becomes Other: A Study of Participation in Armed Groups in South Kivu, Democratic Republic of the Congo', unpublished doctoral dissertation, London School of Economics and Political Science

Marin, M. (2017) 'Amnesty International on Small Tasks, Big Data and Massive Engagement', Exposing the Invisible, https://exposingtheinvisible.org/resources/microtasking-amnesty-international (accessed 8 May 2017)

Masad, D. (2013) 'How Computers Can Help Us Track Violent Conflicts - Including Right Now in Syria', The Monkey Cage, 9 July, http://themonkeycage.org/2013/07/09/howcomputers-can-help-us-track-violent-conflicts-including-right-now-in-syria/ (accessed 5 May 2017)

Mc Doom, O. (2013) 'Who Killed in Rwanda's Genocide? Micro-Space, Social Influence and Individual Participation in Intergroup Violence', Journal of Peace Research 50.4: 453-67

Meier, P. (2012) 'Do Liberation Technologies Change the Balance of Power Between Repressive States and Civil Society?', unpublished PhD thesis, Fletcher School of Law and Diplomacy 
Monroy-Hernandez, A. and Palacios, L. (2014) 'Blog del Narco and the Future of Journalism', Culture and Society 79.2: 85-96

Moreno, A.; Garrison, P. and Bhat, K. (2017) 'WhatsApp for Monitoring and Response during Critical Events: Aggie in the Ghana 2016 Election', Proceedings of the ISCRAM Conference

O'Donnell, A. (2015) 'A Rights Based Approach to Responsible Data', Policy and Practice Blog, Oxfam, http://policy-practice.oxfam.org.uk/blog/2015/08/a-rights-based-approachto-treating-data-responsibly (accessed 5 May 2017)

OECD (2009) Preventing Violence, War and State Collapse: The Future of Conflict Early Warning and Response, Paris: Organisation for Economic Co-operation and Development

Orton, K. (2015) 'As Another Activist is Murdered, The Least We Owe "Raqqa is Being Slaughtered Silently" Is Our Attention', The Independent, 17 December, www.independent.co.uk/voices/the-activists-of-raqqa-is-being-slaughtered-silently-paywith-their-lives-to-expose-isis-the-least-a6777601.html (accessed 5 May 2017)

Oxfam (2015) Oxfam Responsible Program Data Policy, http://policy-practice.oxfam.org.uk/ publications/oxfam-responsible-program-data-policy-575950 (accessed 5 May 2017)

Peuchaud, S. (2014) 'Social Media Activism and Egyptians' Use of Social Media to Combat Sexual Violence', Health Promotion International 29.1: 113-20

Pieterse, J. (2010) Development Theory, London: Sage

Piketty, T. (2014) Capital in the Twenty-First Century, New York: Harvard University Press

Poveda, S. (2016) 'Conscientisation and Human Development: The Case of Digital Inclusion Programmes in Brazil', unpublished PhD thesis, University of London

Price, M.; Klinger, J. and Ball, P. (2013) Preliminary Statistical Analysis of Documentation of Killings in the Syrian Arab Republic, Benetech Human Rights Program, www.ohchr.org/Documents/Countries/SY/PreliminaryStatAnalysisKillingsInSyria.pdf (accessed 5 May 2017)

Read, R.; Taithe, B. and Mc Ginty, R. (2016) 'Data Hubris? Humanitarian Information Systems and the Mirage of Technology', Third World Quarterly 37.8: 1314-31

Reuters (2016) 'Congo asks Companies to Block Social Media before Anti-Kabila Protests', Reuters, 15 December, www.reuters.com/article/us-congo-politics-telecomsidUSKBN14420M (accessed 5 May 2017)

Roberts, T. (2017) 'Digital Technologies Exclude', Making All Voices Count blog, 2 May, www.makingallvoicescount.org/blog/digital-technologies-exclude/ (accessed 5 May 2017)

Salathé, M. et al. (2012) ‘Digital Epidemiology’, PLoS computational biology 8

Sambuli, N.; Crandall, A.; Costello, P. and Orwa, C. (2013) Viability, Verification, Validity: 3Vs of Crowdsourcing, Nairobi: iHub Research 
Sanchez de la Sierra, R. (2017) 'On the Origins of States: Stationary Bandits and Taxation in Eastern DRC', unpublished

Schutte, S. and Weidmann, N. (2011) 'Diffusion Patterns of Violence in Civil Wars', Political Geography 30.3: 143-52

Skalli, L. (2014) 'Young Women and Social Media Against Sexual Harassment in North Africa', The Journal of North African Studies 19.2: 244-58

Statistica (2017) 'Global Social Media Statistics', Smart Insights, www.smartinsights.com/social-media-marketing/social-media-strategy/new-globalsocial-media-research/ (accessed 5 May 2017)

Strasser, M. (2013) ‘Oblivion By Design: Drones and Social Media', Full Stop Media Publishing, 7 January, www.full-stop.net/2013/01/07/blog/max-strasser/oblivion-bydesign-drones-and-social-media/ (accessed 5 May 2017)

Tavaana, 'Ushahidi: From Crisis Mapping Kenya to Mapping the Globe', Tavaana, https://tavaana.org/en/content/ushahidi-crisis-mapping-kenya-mapping-globe (accessed 5 May 2017)

The Guardian (2016) 'British Army Creates Army of Facebook Warriors' The Guardian, 31 January, www.theguardian.com/uk-news/2015/jan/31/british-army-facebookwarriors-77th-brigade (accessed 5 May 2017)

The Guardian (2015) 'Media Distortion and Western Bias - Why Do Some Disasters Attract More Cash', The Guardian, 2 December, www.theguardian.com/globaldevelopment/2014/dec/02/students-speak-media-distortion-western-bias-disasters (accessed 28 April 2017)

Toyama, K. (2011) 'Technology as an Amplifier in International Development', Conference Proceedings, iConference 2011

Tsatsou, P. (2009) 'Reconceptualising "Time" and "Space" in the Era of Electronic Media and Communications', Platform Journal of Media and Communication 1: 11-32

Tufekci, Z. (2014) 'Big Questions for Social Media Big Data: Representativeness, Validity and Other Methodological Pitfalls', in ICWSM '14: Proceedings of the $8^{\text {th }}$ International AAAl Conference on Weblogs and Social Media

United Nations (2013) A New Global Partnership: Eradicate Poverty and Transform Economies through Sustainable Development: Report of the High Level Panel on the Post-2015 Development Agenda, New York: United Nations

Unver, A. and Alasaad, H. (2016) 'How Turks Mobilized Against the Coup: The Power of the Hashtag and the Mosque', Foreign Affairs, 14 September, www.foreignaffairs.com/ articles/2016-09-14/how-turks-mobilized-against-coup (accessed 5 May 2017)

Unwin, T. (2009) ICT4D: Information and Communications for Development, Cambridge: Cambridge University Press

USAID (2013) Connecting to Opportunity: A Survey of Afghan Women's Access to Mobile Phones, Washington DC: United States Agency for International Development 
Van der Windt, P and Humphreys, M. (2016) 'Crowdseeding in Eastern Congo: Using Cell Phones to Collect Conflict Events Data in Real Time', Journal of Conflict Resolution 60.4: 748-81

WeAreSocial (2017) 'Digital in 2017 Global Overview of Social Media Use', WeAreSocial, 24 January, https://wearesocial.com/uk/blog/2017/01/digital-in-2017-global-overview (accessed 28 April 2017)

Weidmann, N. (2015) 'On the Accuracy of Media-Based Conflict Event Data', Journal of Conflict Resolution 59.6: 1129-49

Wijayatilake, K. and Gunaratne, C. (1999) Monitoring Progress in the Elimination of Discrimination Against the Achievement of Equality for Women, Colombo: Centre for Women's Research

Wilson, J. and Gapsiso, N. (2016) Overcoming Gender Inequalities Through Technology Integration, Hersey: IGI Global

Wood, E.J. (2008) 'The Social Processes of Civil War: The Wartime Transformation of Social Networks', Annual Review of Political Science 11: 539-61

Wood, E.J. (2003) Insurgent Collective Action and Civil War in El Salvador, Cambridge: Cambridge University Press

World Bank (2011) ICT in Agriculture: Connecting Smallholders to Knowledge, Networks, and Institutions, World Bank Report Number 64605, www.cto.int/wpcontent/themes/solid/ layout/dc/k-r/ICT in Ag Sourcebook web light.pdf (accessed 5 May 2017)

Ya'u, Y.Z. (2004) 'The New Imperialism and Africa in the Global Electronic Village', Review of African Political Economy 31.99: 11-29

ZCSO (2009) Zambian Demographic Household Survey for 2007, Lusaka: Ministry of Health

Zhuo, X.; Wellman, B. and Yu, J. (2011) ‘Egypt: The First Internet Revolt?', Peace Magazine: $6-10$ 